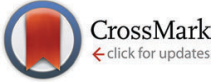

Cite this: Chem. Commun., 2016, 52,7878

Received 20th April 2016, Accepted 20th May 2016

DOI: $10.1039 / c 6 c c 03316 d$

www.rsc.org/chemcomm

\section{Sequential bottom-up and top-down processing for the synthesis of transition metal dichalcogenide nanosheets: the case of rhenium disulfide $\left(\operatorname{ReS}_{2}\right) \dagger$}

\author{
Naktal Al-Dulaimi, $\ddagger^{\mathrm{a}}$ Edward A. Lewis, $\ddagger^{\mathrm{b}}$ David J. Lewis,,$^{\mathrm{ab}}$ Simon K. Howell, \\ Sarah J. Haigh ${ }^{b}$ and Paul O'Brien*ab
}

\begin{abstract}
Bottom-up (aerosol-assisted chemical vapor deposition, AACVD) and top-down (liquid phase exfoliation, LPE) processing methodologies are used in tandem to produce colloids of few-layer thick rhenium disulfide $\left(\mathrm{ReS}_{2}\right)$ in $\mathrm{N}$-methyl pyrrolidone. The processing route we use is a potentially robust and scalable pathway to manufacture useful 2D materials.
\end{abstract}

Rheniite (rhenium disulfide, $\operatorname{ReS}_{2}$ ) is a naturally occurring yet extremely rare transition metal dichalcogenide (TMDC). ${ }^{1}$ Like other TMDCs it has a layered crystal structure (Fig. 1); with a preference for pinacoidal cleavage. In most common TMDCs such as molybdenum disulfide $\left(\mathrm{MoS}_{2}\right)$, the metal spacing is regular and can be simply described by conventional packing. However, the $\mathrm{ReS}_{2}$ crystal structure is more complex because metal-metal interactions contribute significantly to the interlayer bonding, leading to the formation of a repeating motif of Re-parallelograms of varying sizes within the metal layer. ${ }^{2}$

Very recently, there has been some interest in $\mathrm{ReS}_{2}$ as a twodimensional semiconductor. $\mathrm{ReS}_{2}$ is a direct tunable band gap semiconductor, from $1.47 \mathrm{eV}$ in the bulk to $1.61 \mathrm{eV}$ as a monolayer and shows evidence of birefringent behavior. ${ }^{3}$ The band gap energy is predicted to be insensitive to strain, and thus the material may be tolerant to a range of processing methods. ${ }^{4}$ It has been proposed that these favourable properties arise from interlayer decoupling caused by Peierls distortion of the $1 T$ structure of $\mathrm{ReS}_{2}$, which precludes ordered stacking and minimizes wavefunction overlap. ${ }^{5}$ Raman spectra of $\mathrm{ReS}_{2}$ have been shown to be both anisotropic and dependent on the

\footnotetext{
${ }^{a}$ School of Chemistry, University of Manchester, Manchester, M13 9PL, UK.

E-mail: paul.o'brien@manchester.ac.uk; Tel: +44 1612754653

${ }^{b}$ School of Materials, University of Manchester, Manchester, M13 9PL, UK

${ }^{c}$ School of Physics, University of Manchester, Manchester, M13 9PL, UK

$\dagger$ Electronic supplementary information (ESI) available: Characterization of $\left[\operatorname{Re}\left(\mathrm{S}_{2} \mathrm{CC}_{6} \mathrm{H}_{5}\right)\left(\mathrm{S}_{3} \mathrm{CC}_{6} \mathrm{H}_{5}\right)_{2}\right]$. Characterization of $\mathrm{ReS}_{2}$ thin film produced by AACVD by PXRD, SEM and Raman spectroscopy. Additional atomic-resolution HAADF STEM images, summed energy dispersive X-ray (EDX) spectrum from elemental imaging of nanosheets. See DOI: 10.1039/c6cc03316d

\$ Contributed equally.
}
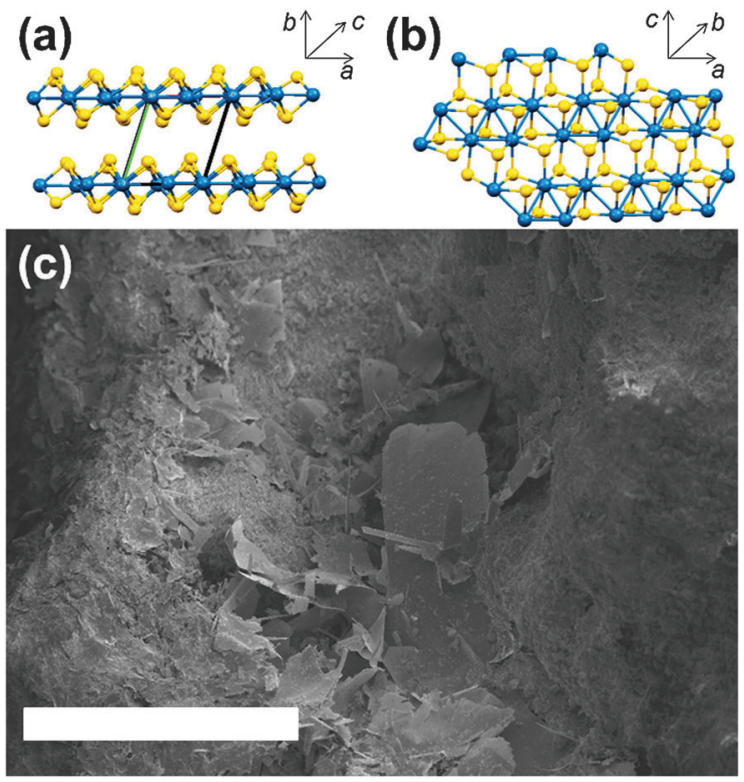

Fig. 1 Structure of rheniite (rhenium disulfide, $\operatorname{ReS}_{2}$ ). (a) The crystal structure of $\operatorname{ReS}_{2}$, showing the triclinic unit cell $(a=6.378 \AA, b=6.417 \AA$, $c=6.461 \AA$ with $\alpha=91.62^{\circ}, \beta=119.07^{\circ}, \gamma=105.115^{\circ}$ ). (b) A monolayer of $\operatorname{ReS}_{2}$ looking along the [010] zone axis. (c) Secondary electron SEM image (6 kV) of a sample of rheniite from Kudriavy volcano type locality showing the sheet-like crystals typical of the layered mineral. Scale bar represents $1 \mathrm{~mm}$.

number of layers in the material. ${ }^{6,7}$ Current routes to $\mathrm{ReS}_{2}$ monolayers are not ideal as they either rely on chemical vapor deposition processes requiring high vacuum, ${ }^{8,9}$ or harsh chemical exfoliation with organolithium species. ${ }^{10}$

Aerosol-assisted chemical vapor deposition (AACVD) ${ }^{11}$ from single source precursors is a versatile route to produce pure metal chalcogenide thin films such as tin(II) sulfide (SnS), ${ }^{12}$ cadmium sulfide (CdS) ${ }^{13}$ pyrite $\left(\mathrm{FeS}_{2}\right),{ }^{14-16}$ molybdenum disulfide $\left(\mathrm{MoS}_{2}\right)$ as well as to produce related (e.g. Cr-doped) variants. ${ }^{17-19}$ Additionally a range of useful metal oxides $\mathrm{s}^{6,7,20-24}$ and organohalide lead(II) perovskites have been reported. ${ }^{25-27}$ AACVD can take place at moderate temperature, at ambient pressure and is inherently 
scalable. We have recently reported the production of polycrystalline thin films of $\mathrm{ReS}_{2}$ using AACVD from a single source precursor. $^{28}$

In general, two-dimensional (2D) materials such as graphene ${ }^{29}$ and 2D $\mathrm{TMDCs}^{30}$ are produced for demonstrative studies using mechanical (scotch tape) exfoliation. More recently, liquid-phase exfoliation (LPE) has emerged as a more scalable and versatile solution-phase processing methodology to produce industrially
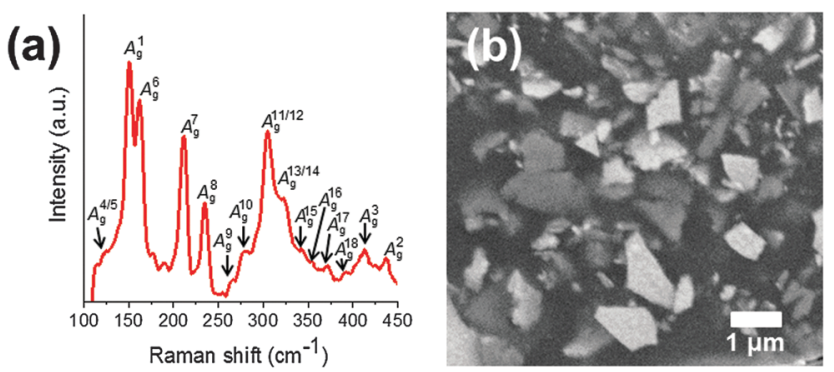

Fig. 2 Characterization of $\mathrm{ReS}_{2}$ nanosheets exfoliated from thin films of $\mathrm{ReS}_{2}$ grown by AACVD at $550{ }^{\circ} \mathrm{C}$. (a) Raman spectrum of exfoliated nanosheets drop cast from NMP on $\mathrm{Si} a \mathrm{SiO}_{2}$ substrates with peaks labelled using the scheme proposed by Pradhan et al. ${ }^{21}$ (b) Secondary electron SEM image $(6 \mathrm{kV})$ of $\mathrm{ReS}_{2}$ nanosheets drop cast from NMP onto $\mathrm{Si}_{2} \mathrm{SiO}_{2}$ substrates. significant quantities of nanomaterials ranging from graphene, ${ }^{31}$ TMDCs, ${ }^{32}$ phosphorene $^{33}$ and 2D tin(II) sulfide. ${ }^{34}$ Negatively charged $\mathrm{ReS}_{2}$ nanosheets have been reported by Chen and co-workers using lithium intercalation-exfoliation. ${ }^{35}$ In this paper we present the marriage of a scalable bottom-up process (AACVD) with top-down LPE as a new scalable processing route to produce atomically thin materials, in this case few-layer $2 \mathrm{D} \mathrm{ReS}_{2}$.

$\mathrm{ReS}_{2}$ thin films were produced by AACVD on glass substrates at $550{ }^{\circ} \mathrm{C}$ using the single source precursor $\left.\left[\mathrm{Re}\left(\mathrm{S}_{2} \mathrm{CC}_{6} \mathrm{H}_{5}\right)\left(\mathrm{S}_{3} \mathrm{CC}_{6} \mathrm{H}_{5}\right)_{2}\right]\right]^{36}$ Characterization of the films by Raman spectroscopy agreed with the previously reported spectra for $\operatorname{ReS}_{2}{ }^{5,28}$ and powder X-ray diffraction (pXRD) measurements showed a preferred orientation in the (010) plane whilst scanning electron microscopy (SEM) revealed the lamellar morphology of the individual crystallites within the thin film. EDX spectrum mapping of the $\operatorname{Re} \mathrm{L}_{\alpha}$ (8.6 keV) and $\mathrm{S} \mathrm{K}_{\alpha}(2.3 \mathrm{keV})$ lines demonstrated the homogeneous co-localisation of both elements in the thin film. Atomic force microscopy (AFM) at the film-edge was used to measure the thickness of the film as $150 \pm 50 \mathrm{~nm}$. The above evidence for $\mathrm{ReS}_{2}$ film formation is given fully in the ESI. $\dagger$ All of the characterisation data from the thin films were consistent with that observed previously for $\mathrm{ReS}_{2}$ films produced by AACVD. ${ }^{28}$ The thin films were then immersed in $N$-methyl-2pyrrolidone (NMP) and ultrasonicated for $36 \mathrm{~h}$, using similar
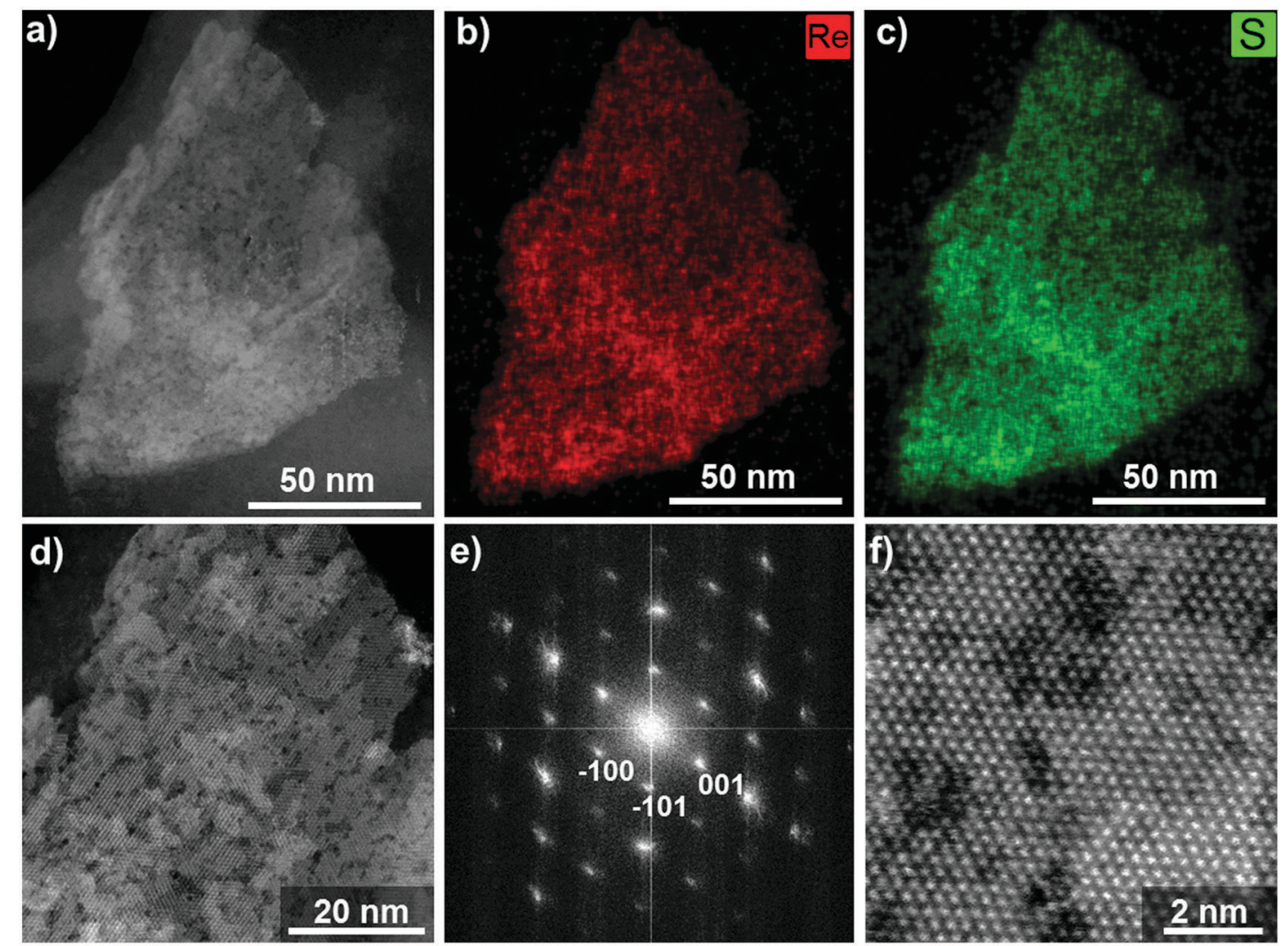

Fig. 3 (a) HAADF STEM image of a representative LPE flake of ReS $S_{2}$ grown by AACVD at $550{ }^{\circ} \mathrm{C}$. Corresponding EDX elemental maps showing (b) Re $L_{\alpha}$ $(8.6 \mathrm{keV})$ and (c) $\mathrm{S} \mathrm{K} \mathrm{K}_{\alpha}(2.3 \mathrm{keV}) \mathrm{X}$-ray counts demonstrate co-localisation of Re and S, the summed EDX spectrum can be found in the ESI. $\dagger$ (d) Atomic resolution HAADF STEM image of a region of the flake shown in (a). (e) Fourier transform of (d), confirming the expected crystal structure for ReS 2 viewed down the [010] zone axis and demonstrating that the entire nanosheet is a single crystal. (f) Shows a higher magnification image of the same flake so that the atomic structure can be clearly seen. 
conditions to that reported previously for liquid exfoliation of other 2D materials. ${ }^{33,34}$ The resulting colloidal suspension of nanosheets was drop-casted onto silicon wafers coated with $300 \mathrm{~nm}$ of silicon dioxide $\left(\mathrm{Si} @ \mathrm{SiO}_{2}\right)$ for analysis.

Raman spectroscopy of $\mathrm{ReS}_{2}$ nanosheets on $\mathrm{Si@SiO} \mathrm{S}_{2}$ substrates showed signals of a weak intensity associated with $\operatorname{ReS}_{2}$; optical phonon modes are observed at ca. 150, 163, 212, 235 and $305 \mathrm{~cm}^{-1}$ (Fig. 2a), as previously reported. A total of 18 phonon modes, which have previously been attributed to vibrations of $A_{g}$ symmetry, ${ }^{21}$ were identified. As all the modes were observed at once, we conclude that a number of randomly orientated flakes were sampled during the measurement, as the Raman response from $\mathrm{ReS}_{2}$ has been shown to be anisotropic for large mechanically exfoliated flakes. ${ }^{6,21}$ There are some subtle differences in the Raman spectrum of the nanosheets compared to that of the bulk thin film: the $\mathrm{A}_{\mathrm{g}}^{1}$ mode shifts from $148.5 \mathrm{~cm}^{-1}$ to $150.4 \mathrm{~cm}^{-1}$ whilst the $A_{\mathrm{g}}^{7}$ mode shifts from 207.8 to $211.6 \mathrm{~cm}^{-1}$ in going from bulk to nanosheet form. These shifts are consistent with those found by Hone and co-workers for micromechanically exfoliated $\mathrm{ReS}_{2}$ compared with bulk $\mathrm{ReS}_{2}{ }^{6}$ Secondary electron scanning electron microscopy (SEM) images at $6 \mathrm{kV}$ reveal nanosheets of up to $1 \mu \mathrm{m}$ in length/width (Fig. 2b), though there are many smaller nanosheets found in the sample, typically $<500 \mathrm{~nm}$. The smaller sheet size from LPE sols is typical for TMDCs produced by this method compared to mechanical exfoliation, where sheet size can be in the micron range. $^{10}$

High-angle annular dark field scanning transmission electron microscope (HAADF STEM) images of the $\mathrm{ReS}_{2}$ nanosheets show that they are highly crystalline (Fig. 3). The calculated rhenium positions of octahedral (T) $\operatorname{ReS}_{2}$ as-viewed down the [010] zone axis of can be overlaid on the atomic resolution images and both match perfectly (ESI $\dagger$ ). Fast Fourier transforms taken from these atomic resolution HAADF images of individual flakes demonstrate that the sheets are comprised of single crystals of $\operatorname{ReS}_{2}$. Energy dispersive X-ray (EDX) elemental mapping of the Re $\mathrm{L}_{\alpha}(8.6 \mathrm{keV})$ (Fig. 3b) and $\mathrm{S} \mathrm{K}_{\alpha}(2.3 \mathrm{keV}$ ) (Fig. 3c) X-ray counts show the expected co-localisation of Re and $\mathrm{S}$ within the boundary of the flakes.

Atomic force microscopy (AFM) was used to analyse the heights of the $\mathrm{ReS}_{2}$ flakes produced by our novel method (Fig. 4). It was found that the flakes ranged in height from 1-20 nm. Significant populations of monolayer (ca. $1.7 \mathrm{~nm})$, bilayer $(3.9 \mathrm{~nm})$ and trilayer $(6.0 \mathrm{~nm})$ flakes were observed along with larger flakes with heights up to $c a .20 \mathrm{~nm}$, i.e. up to 10-layers, though the thinnest flakes do represent the majority of the population analysed under these conditions.

Hence, we conclude that the exfoliation procedure successfully produces ultrathin and crystalline $\mathrm{ReS}_{2}$ sheets from $\mathrm{ReS}_{2}$ thin films grown by AACVD. Our $\mathrm{ReS}_{2}$ nanosheets are identical in phase to those reported previously by Chen and co-workers and have similar thickness, ${ }^{35}$ but with the added advantage that there is no lithium associated with them (i.e. should be neutral compared to the negatively charged sheets produced by lithium intercalationexfoliation) and do not require post-exfoliation modification.

In summary, we have coupled the bottom up processing of $\mathrm{ReS}_{2}$ by AACVD with top-down LPE to produce ultrathin $\operatorname{ReS}_{2}$

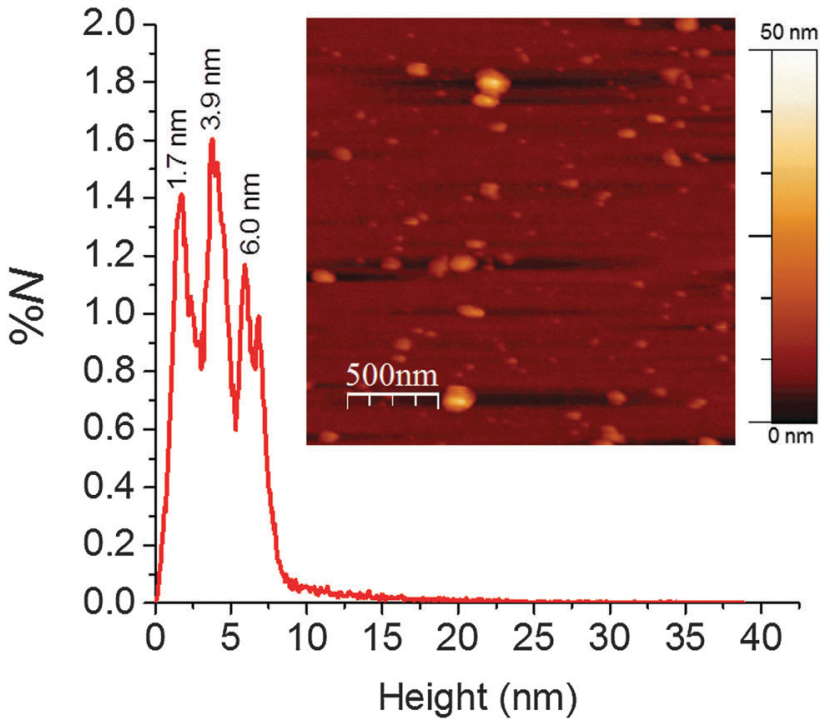

Fig. 4 Particle size distribution of $\mathrm{ReS}_{2}$ nanosheets exfoliated from thin films of $\mathrm{ReS}_{2}$ grown by AACVD at $550{ }^{\circ} \mathrm{C}$ as-measured by AFM showing significant peaks at 1.7, 3.9 and $6.0 \mathrm{~nm}$. Inset: Representative height profile AFM image of exfoliated $\mathrm{ReS}_{2}$ nanosheets spin coated from NMP suspension onto a $\mathrm{Si} \mathrm{SiO}_{2}$ substrate.

nanosheets. In the case of $\mathrm{ReS}_{2}$, which is a useful $2 \mathrm{D}$ semiconductor, this is important as natural sources are scarce and synthetic pathways are required. Additionally our processing methodology is potentially scalable and thus could be a route to commercial exploitation. Finally, the serial processing we report here is potentially applicable to a wide range of layered TMDC materials. It will be useful in the future for the production of a myriad of synthetic TMDC materials with interesting optoelectronic properties which are complementary to graphene. As it has been established that doping of TMDCs is possible by AACVD,${ }^{18}$ there may also be scope to produce doped 2D materials in the future which are interesting for a range of applications. ${ }^{19}$

N. Al-D. thanks the Higher Committee for Education Development in Iraq (HCED) for funding and support, and also, the Chemistry Department and University of Sulaimani, Iraq, for allowing a period of study in the U.K. Some of the equipment used in this study was provided by the Engineering and Physical Sciences Research Council U.K. (Core Capability in Chemistry, EPSRC grant number EP/K039547/1). S. J. H. and E. A. L. thank the US Defense Threat Reduction Agency and the EPSRC for the award of a Doctoral Prize to E. A. L.

\section{Notes and references}

1 M. A. Korzhinsky, S. I. Tkachenko, K. I. Shmulovich, Y. A. Taran and G. S. Steinberg, Nature, 1994, 369, 51-52.

2 H. H. Murray, S. P. Kelty, R. R. Chianelli and C. S. Day, Inorg. Chem., 1994, 33, 4418-4420.

3 O. B. Aslan, D. A. Chenet, A. M. van der Zande, J. C. Hone and T. F. Heinz, ACS Photonics, 2016, 3, 96-101.

4 Z. G. Yu, Y. Cai and Y.-W. Zhang, Sci. Rep., 2015, 5, 13783.

5 S. Tongay, H. Sahin, C. Ko, A. Luce, W. Fan, K. Liu, J. Zhou, Y.-S. Huang, C.-H. Ho, J. Yan, D. F. Ogletree, S. Aloni, J. Ji, S. Li, J. Li, F. M. Peeters and J. Wu, Nat. Commun., 2014, 5, 3252.

6 D. A. Chenet, O. B. Aslan, P. Y. Huang, C. Fan, A. M. van der Zande, T. F. Heinz and J. C. Hone, Nano Lett., 2015, 15, 5667-5672. 
7 R. He, J.-A. Yan, Z. Yin, Z. Ye, G. Ye, J. Cheng, J. Li and C. H. Lui, Nano Lett., 2016, 16, 1404-1409.

8 K. Keyshar, Y. Gong, G. Ye, G. Brunetto, W. Zhou, D. P. Cole, K. Hackenberg, Y. He, L. Machado, M. Kabbani, A. H. C. Hart, B. Li, D. S. Galvao, A. George, R. Vajtai, C. S. Tiwary and P. M. Ajayan, Adv. Mater., 2015, 27, 4640-4648.

9 X. He, F. Liu, P. Hu, W. Fu, X. Wang, Q. Zeng, W. Zhao and Z. Liu, Small, 2015, 11, 5423-5429.

10 M. Chhowalla, H. S. Shin, G. Eda, L.-J. Li, K. P. Loh and H. Zhang, Nat. Chem., 2013, 5, 263-275.

11 P. Marchand, I. A. Hassan, I. P. Parkin and C. J. Carmalt, Dalton Trans., 2013, 42, 9406-9422.

12 P. Kevin, D. J. Lewis, J. Raftery, M. A. Malik and P. O’Brien, J. Cryst. Growth, 2015, 415, 93-99.

13 S. Mlowe, D. J. Lewis, M. A. Malik, J. Raftery, E. B. Mubofu, P. O'Brien and N. Revaprasadu, New J. Chem., 2014, 38, 6073-6080.

14 S. Mlowe, D. J. Lewis, M. A. Malik, J. Raftery, E. B. Mubofu, P. O'Brien and N. Revaprasadu, Dalton Trans., 2016, 45, 2647-2655.

15 S. Khalid, M. A. Malik, D. J. Lewis, P. Kevin, E. Ahmed, Y. Khan and P. O'Brien, J. Mater. Chem. C, 2015, 3, 12068-12076.

16 S. Khalid, E. Ahmed, M. A. Malik, D. J. Lewis, S. Abu Bakar, Y. Khan and P. O'Brien, New J. Chem., 2015, 39, 1013-1021.

17 A. A. Tedstone, D. J. Lewis, R. Hao, S.-M. Mao, P. Bellon, R. S. Averback, C. P. Warrens, K. R. West, P. Howard, S. Gaemers, S. J. Dillon and P. O'Brien, ACS Appl. Mater. Interfaces, 2015, 7, 20829-20834.

18 D. J. Lewis, A. A. Tedstone, X. L. Zhong, E. A. Lewis, A. Rooney, N. Savjani, J. R. Brent, S. J. Haigh, M. G. Burke, C. A. Muryn, J. M. Raftery, C. Warrens, K. West, S. Gaemers and P. O'Brien, Chem. Mater., 2015, 27, 1367-1374.

19 A. A. Tedstone, D. J. Lewis and P. O'Brien, Chem. Mater., 2016, 28, 1965-1974.

20 D. S. Bhachu, D. O. Scanlon, G. Sankar, T. D. Veal, R. G. Egdell, G. Cibin, A. J. Dent, C. E. Knapp, C. J. Carmalt and I. P. Parkin, Chem. Mater., 2015, 27, 2788-2796.

21 N. R. Pradhan, A. McCreary, D. Rhodes, Z. Lu, S. Feng, E. Manousakis, D. Smirnov, R. Namburu, M. Dubey, A. R. Hight Walker, H. Terrones, M. Terrones, V. Dobrosavljevic and L. Balicas, Nano Lett., 2015, 15, 8377-8384.
22 S. Q. Chen, M. McLachlan, A. Sapelkin and R. Binions, J. Mater. Chem. A, 2015, 3, 22311-22315.

23 S. Q. Chen, R. M. Wilson and R. Binions, J. Mater. Chem. A, 2015, 3, 5794-5797.

24 A. J. Gardecka, G. K. L. Goh, G. Sankar and I. P. Parkin, J. Mater. Chem. A, 2015, 3, 17755-17762.

25 D. S. Bhachu, D. O. Scanlon, E. J. Saban, H. Bronstein, I. P. Parkin, C. J. Carmalt and R. G. Palgrave, J. Mater. Chem. A, 2015, 3, 9071-9073.

26 S. Q. Chen, J. Briscoe, Y. Shi, K. Chen, R. M. Wilson, S. Dunna and R. Binions, CrystEngComm, 2015, 17, 7486-7489.

27 D. J. Lewis and P. O'Brien, Chem. Commun., 2014, 50, 6319-6321.

28 N. Al-Dulaimi, D. J. Lewis, X. L. Zhong, M. Azad Malik and P. O'Brien, J. Mater. Chem. C, 2016, 4, 2312-2318.

29 K. S. Novoselov, A. K. Geim, S. V. Morozov, D. Jiang, Y. Zhang, S. V. Dubonos, I. V. Grigorieva and A. A. Firsov, Science, 2004, 306, 666-669.

30 K. S. Novoselov, D. Jiang, F. Schedin, T. J. Booth, V. V. Khotkevich, S. V. Morozov and A. K. Geim, Proc. Natl. Acad. Sci. U. S. A., 2005, 102, 10451-10453.

31 Y. Hernandez, V. Nicolosi, M. Lotya, F. M. Blighe, Z. Sun, S. De, I. T. McGovern, B. Holland, M. Byrne, Y. K. Gun'ko, J. J. Boland, P. Niraj, G. Duesberg, S. Krishnamurthy, R. Goodhue, J. Hutchison, V. Scardaci, A. C. Ferrari and J. N. Coleman, Nat. Nanotechnol., 2008, 3, 563-568.

32 J. N. Coleman, M. Lotya, A. O'Neill, S. D. Bergin, P. J. King, U. Khan, K. Young, A. Gaucher, S. De, R. J. Smith, I. V. Shvets, S. K. Arora, G. Stanton, H.-Y. Kim, K. Lee, G. T. Kim, G. S. Duesberg, T. Hallam, J. J. Boland, J. J. Wang, J. F. Donegan, J. C. Grunlan, G. Moriarty, A. Shmeliov, R. J. Nicholls, J. M. Perkins, E. M. Grieveson, K. Theuwissen, D. W. McComb, P. D. Nellist and V. Nicolosi, Science, 2011, 331, 568-571.

33 J. R. Brent, N. Savjani, E. A. Lewis, S. J. Haigh, D. J. Lewis and P. O'Brien, Chem. Commun., 2014, 50, 13338-13341.

34 J. R. Brent, D. J. Lewis, T. Lorenz, E. A. Lewis, N. Savjani, S. J. Haigh, G. Seifert, B. Derby and P. O'Brien, J. Am. Chem. Soc., 2015, 137, 12689-12696.

35 T. Fujita, Y. Ito, Y. Tan, H. Yamaguchi, D. Hojo, A. Hirata, D. Voiry, M. Chhowalla and M. Chen, Nanoscale, 2014, 6, 12458-12462.

36 C. A. McConnachie and E. I. Stiefel, Inorg. Chem., 1997, 36, 6144-6145. 